\title{
The perspective of using MOOCs in journalism education: Case study of mobile journalism MOOC users' experiences
}

\author{
Petra Kovačević ${ }^{1}$ \\ University of Cardiff, School of Journalism, Media and Cultural Studies, UK \\ Tena Perišin ${ }^{2}$ \\ University of Zagreb, Faculty of Political Science, Croatia
}

doi: $10.5937 /$ comman 12-15223

Abstract: Through analysing massive open online courses (MOOC) participants' experiences and perceptions of a 20-week course in mobile journalism, this paper examines the potential obstacles, challenges and opportunities in providing education in this specific field. Results confirm the problematic low retention rate for MOOCs and show that this type of course demands more effort from participants by asking them to complete practical assignments away from the comfort of their homes. The content of the course, as well as quality communication with tutors is key for motivation and progress of participants in this MOOC. Consideration of technical resources for this type of remote training (smartphones and other equipment) is recommended, along with more interactive sessions that enhance the learning experience by connecting closer not only participants with tutors but participants with each other.

Keywords: mobile journalism, video journalism, massive open online courses, remote learning, participation

\footnotetext{
1 Contact with author: KovacevicP@cardiff.ac.uk.

2 Contact with author: tena.perisin@gmail.com.
} 


\section{Introduction}

In today's hectic and ever-changing world, the responsibility of journalism is bigger than ever before: to explain the world to their audiences, but in the same time to adapt to it itself. While newsrooms and journalists have been coming to terms with the benefits and threats of digital technologies and social media, journalism schools have been trying to prepare future journalists for this impermanent environment. Huge shifts in the expected skills and journalism business practices have posed a significant challenge to journalism educators. Only recently have they begun to embrace digital technologies in their work with students, examining different possibilities of teaching students both the fundamentals of journalism and the practical skills of recording, producing and editing audio, video or other visual materials.

In the recent years, online learning has become a new platform to additionally engage students in higher education, as well as to provide learning opportunities to those who might otherwise be unable to attend be it for lack of time, money or a significant geographical distance. One learning format that tried to enable this are massive open online courses (MOOCs).

Journalism department of the Faculty of Political Science in Zagreb, as part of one Erasmus+ project, is involved in the creation and provision of a free MOOC that seeks to teach and empower European youth the basic knowledge and skills in mobile journalism (MoJo). MoJo is one of the skills expected in newsrooms of young journalists both in traditional media newsrooms and freelance work. This MOOC puts a special emphasis on teaching all the necessary practical skills to do mobile journalism with the aim to encourage active participation and the citizenship of the young people. It is a. part of the wider project Y-NEX (Youth News Exchange) which has been launched in October 2015 (Kovačević \& Perišin, 2016) with the aim to empower active citizenship of the young people. The first objective was to develop a new training program in mobile journalism. The use of MOOCs in mobile journalism education has not yet been explored. The aim of this research is to investigate the experiences and uses of this mobile journalism MOOC among its participants in order to examine the potential of this educational approach for mobile journalism learning. This paper examines the usefulness and limitations of this type of MOOCs in order to teach additional journalistic practical skills, as well as pro- 
vide recommendations on how to approach, connect with and motivate remote students with more success and create more engaging MOOC content to teach hands-on journalistic skills, specifically mobile journalism.

\section{Literature review: MOOCs in education}

Massive Open Online Courses (MOOCs) are a growing model of remote education that erases geographical, social and financial boundaries. "MOOC integrates the connectivity of social networking, the facilitation of an acknowledged expert in a field of study, and a collection of freely accessible online resources" (McAuley et al., 2010: 4). MOOC is different from online education as it is free and open, not reserved for a chosen group of remote participants, but a larger and more diverse audience. Daradoumis et al. (2013: 208) see MOOCs as a powerful tool for active engagement of these self-organizing learners who connect through the course platform and other available social interaction tools. Aharony and Bar-Ilan (2016: 146) sum up the unique features of MOOCs as massiveness, openness and peer assessment.

Even though MOOCs are seen as a new educational resource that many institutions decide to invest in, one of the most cited issue is a low rate of completion, on average around 10 percent or less (Breslow et al., 2013; Alraimi et al., 2015). Predictors of MOOC retention, as examined by Hone and El Said (2016) in their survey study, are content and interaction with tutors. A substantial amount of academic research, predominantly case studies, have been dedicated to exploration of motivations and satisfaction of MOOC users in order to improve the effectiveness of these courses. As found by Alraimi et al. (2015: 34), success of a MOOC course or the strongest predictor of intention to continue or complete a course are the perceived reputation of the institution providing the course, followed by perceived openness, satisfaction, usefulness and enjoyment. People enrol in MOOCs to extend their knowledge, because they are curious, because they see it as a way of setting a personal challenge or because they want to complete it and gather a certificate (Hew \& Cheung 2014). MOOCs are also appreciated among participants for its ease of use and perceived usefulness of content of the course (Aharony \& Bar-Illan, 2016: 157). 


\section{New models of journalism education}

Journalism education developed with the rise of mass media when journalists had to find information and shape it in an accurate story for a large and unknown audience. Carey (2000: 13) calls it the "age of the reporter" when curriculums duplicated the atmospherics of newspapers. While the idealized perception of journalism education today still focuses on reporters who gather, evaluate, produce and distribute information, many who graduate journalism today do not end up reporting stories (Mensing, 2010: 511). New technological opportunities and challenges, along with a new and more empowered role of now more fragmented and demanding audience, has shaken up both journalists and journalism educators. New available technologies shape not only the way journalism is done, but offer new ways of teaching and raising future journalists. This inspired recommendations of new models for journalism education. While Mensing (2010) asks for a shift of focus from the industry to the community, which implies developing new journalistic and practical skills dedicated to serving the community and using the advantages of new technologies for it; Gillmor (2016) suggests a more holistic model that would first bring media literacy to every level of education, bring journalism schools closer to their communities and train citizen journalists to understand and apply sound journalistic principles and best practices. Gillmor (2016: 817) uses MOOCs at Arizona State University in order to teach media literacy skills to journalism students and people outside the field, while in his model he overall pinpoints online learning as an essential tool of teaching journalists of tomorrow.

The topic of media literacy has taken off with the arrival of new technologies that have been affecting both the way audiences consume and understand media content and the ways in which it is produced (Koltay, 2011). "Technology has created a new economic organization of journalism in which the norms of journalism are being pulled and redefined, and sometimes abandoned" (Kovach \& Rosenstiel, 2007: 11). The growing pressures of digitalization entered news organizations and brought irreversible changes to the way the functioned and did journalism (Picard, 2006). Conboy and Eldridge (2015) say journalism is in an era of good fortune despite an appearance of rupture, because this helps it to strengthen its sense of core professional responsibilities. One of the most recent skills that arrived to newsrooms - television, radio, newspaper and online - are those of mobile journalism or using smartphones as a tool for 
journalistic storytelling. "Mobile journalism, whereby a single reporter must write, shoot, and edit their own news stories, is a rapidly growing trend among local television news organizations in the United States and around the world" (Blankenship, 2016: 1055). While the incorporation of mobile journalism skills in the newsrooms and on field has been examined by scholars (Mills et al., 2012; Kumar \& Haneef, 2017), how the education of these specific skills have been incorporated into journalism education in order to prepare future professionals for the newsroom, has been under-researched. Kraft and Seely (2015) examined the benefits of incorporating the use of iPads in journalism classroom environment. In the overview of curricula in journalism education in Europe and in the U.S., it seems that mobile journalism skills are incorporated as part of existing modules and mostly cover the practical side of these skills (Kovačević \& Perišin, 2016). At the same time, employers in media seek for journalists who are able to use smartphones in news gathering, reporting and interacting with audiences (Wenger, Owens \& Thompson 2014). While journalism education is trying to be relevant in face of the newest challenges in the newsrooms, the potential uses and obstacles of teaching mobile journalism skills through MOOC platforms has not yet been researched. Therefore in this study we aim to examine the potential of providing mobile journalism education on MOOC platforms and seeking the most engaging ways of incorporating this successfully and efficiently in journalism education.

\section{Methodology}

Data for this study were collected through analysis of one specific MOOC course in mobile journalism in two ways:

- By conducting two online surveys as part of an in-depth evaluation of experiences of participants, one in the middle and one close to the end of the course;

- By using available information on participants' activities available through the MOOC platform on which this course was designed and offered.

The MOOC course chosen for analysis was created as part of an Erasmus+ project called European Youth News Exchange (Y-NEX) and based on a curriculum of training in mobile journalism, prior developed as part of the project. 
The MOOC consisted of six modules, each produced by one of the six partners in the project: 1. Media Literacy and Human Rights (developed by Laura Cervi from Universitat Autonoma de Barcelona), 2. Mobile Journalism Technology (developed by Phillip Penny and Linda Carol from the Institute of Art, Design and Technology, Dun Laoghaire), 3. Mobile Journalism Storytelling (developed by Dr Tena Perisin, Dr Igor Kanizaj and Petra Kovacevic from the Faculty of Political Science in Zagreb, Journalism department), 4. Mobile Journalism Production (developed by Darko Flajpan and Dalibor Pokec from the HRT Academy, Croatian Radiotelevision), 5. Copyright and Ethics (developed by Mathy Vanbuel and Sally Reynolds from Belgian ATiT, Audiovisual Technologies, Informatics and Telecommunications) and 6. Digital Entrepreneurship (developed by Zarko Cizmar and Danijel Borna Fiket from Telecentar Croatia).

452 participants were enrolled in this MOOC. It was free and open to anyone from anywhere in the world, but primarily intended for young people who wanted to learn new skills and use them as a tool of empowerment in their community and as an asset for future employability. The course ran from January until June 2017. The platform used for this MOOC was Eliademy, a free and open source platform. Modules consisted of web pages with text materials, videos, resources, quizzes and a discussion forum. Each module ran for four weeks and required of students about four hours of effort per week, including going through the lessons, learning and completing assignments. Each module consisted of four lessons. After each lesson students were asked to complete a task. There were 13 tasks and 4 quizzes, including a special assignment at the end of each module. Students were required to complete it in order to receive a badge, proceed to the next module and to get a certificate of completion at the end of the whole course. Modules one and five required completion of assignments that were written and did not require practical skills: writing an essay, participating in a forum discussion or completing a questionnaire. Assignments in modules two, three and four required practical skills and the use of smartphones or iPhones:

- Taking and editing photographs

- Recording and editing audio clips and audio stories

- Recording and editing video clips and video stories (slow motion video, hyperlapse video, interview, news package, multimedia story) 
For all practical assignments, students were asked to search for topics and stories in the field. Therefore, this MOOC demanded additional effort and its completion was not possible without field work. The exception was the last module which did not include any tasks.

Both online surveys were hosted on SurveyMonkey. All MOOC participants were invited by email to fill it in. The first online survey ran for two weeks in March 2017. 19 participants or 5 percent of enrolled participants at the time completed it. The survey was limited in scope with a main objective to recruit participants for a masterclass which was a part of the project. There were eight statements and the participants were asked to either agree wholeheartedly, agree somewhat, disagree somewhat and disagree. The participants were also given the option to comment their responses to these statements. Additionally, they were asked to comment:

- Tell us what you like most in the MOOC.

- Tell us what you like least in the MOOC.

- If you have already stopped participating in the MOOC, can you tell us why you stopped?

The second online survey was considerably more in-depth. It ran for two weeks in June 2017. 31 participants or 7 percent of all participants completed this survey. This is twice the number of participants who successfully completed the whole MOOC. Out of 452 participants, only 15 completed all the modules and received the certificate of completion. The number of those who completed the survey is low and therefore cannot represent the whole of population who enrolled in this MOOC, however the responses, especially the ones where description was acquired, do offer valuable insights. The survey consisted of 332 data entry points and the average duration for the completion was around 23 minutes.

Mathy Vanbuel from ATiT, a Belgian audiovisual and information technologies company that is one of six partners in the project that designed the MOOC, was in charge of setting up the surveys on Survey Monkey. Based on his rich experience in use of media in education, Vanbuel designed an evaluation report ${ }^{3}$ on the basis of the collected data for the sake of the Y-NEX project.

\footnotetext{
3 This survey evaluation report is an internal document that is publicly available here: https://y-nex.com/. It can also be obtained from the authors of this paper or from MrVanbuel (mathy.vanbuel@atit.be)
} 
This was necessary because the analysed MOOC course in mobile journalism was in its first, pilot edition. The responses of the participants, along with the data on activity on the platform, were guidelines for further improvement of specific modules and the course as a whole. While the questionnaire for the first survey was designed by ATiT, the researchers were in charge of the design of the second questionnaire. The use of the data collected by the first questionnaire, along with the findings in the evaluation report, was provided and given permission by Mathy Vanbuel for the sake of this research.

\section{Results}

\subsection{Enrolment, motivation and actual participation}

The respondents for both surveys came from altogether eight countries: Croatia, Spain, Belgium, Finland, Bangladesh, Egypt, Nigeria and Turkey. While the first survey did not ask for details regarding occupation and participants' motivations, the second survey did. More than 60 percent of respondents were highly educated, holding a bachelor degree, master degree or one of equivalents. 30 percent of respondents were students, 25 percent teachers, 10 percent were unemployed, while other respondents were employed either in media or in education. 55 percent said they had basic knowledge about mobile journalism before starting the course, 26 percent had little knowledge, while 16 percent had no knowledge at all. The motivation to participate was diverse: 32 percent said they were interested in mobile journalism, 28 percent wanted to improve their journalistic skills, 27 percent wanted to acquire mobile production skills, while 13 percent said they did it just for fun.

There were altogether 13,249 interactions by participants (reading a text, playing a video, participation in a discussion or submitting a task), therefore on average each participant interacted 29 times. When we take into account the real active participation, we get a more realistic result: 308 interactions per participant. However, the firmest indicator of the discrepancy between the number of enrolments and the actual participation on the MOOC is the number of submitted assignments on each module is visible from Figure 1. 
Figure 1: Number of submitted assignments per module in the MOOC

\section{Active participation - assignments}

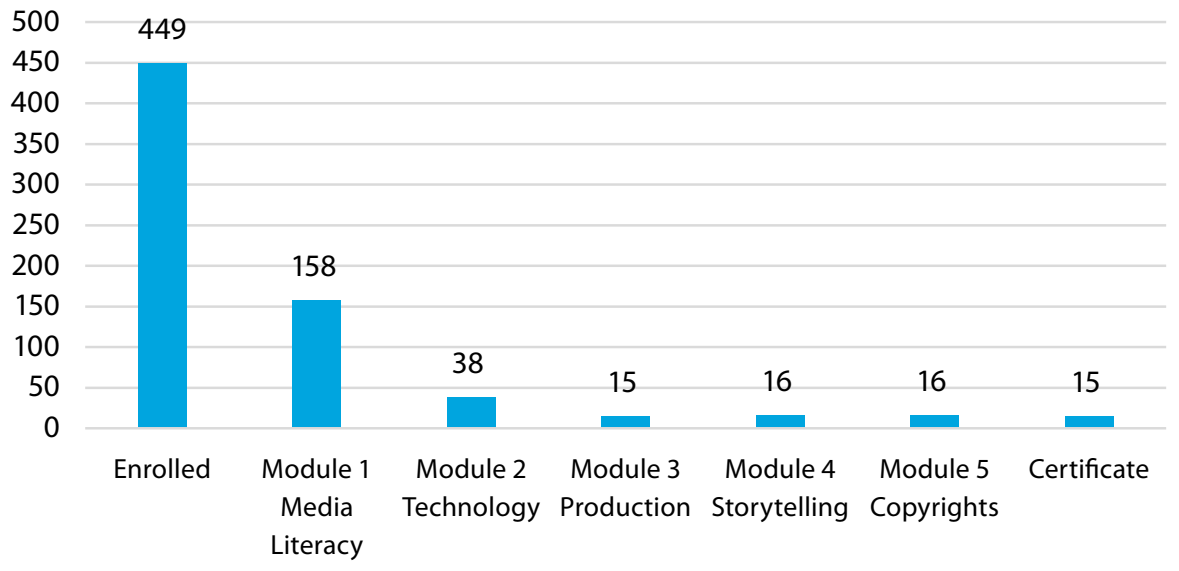

The reasons behind this retention can be partially deduced from the responses in the second survey. As mentioned before, out of 15 participants who completed the whole course, another 16 completed the survey. To the question asked: "If you did not finish all Modules, why did you stop?" lack of free time was predominantly detected as one of the greatest obstacles. Fewer mentioned technical difficulties, such as no WiFi connection needed for completion of some assignments or a smartphone that broke down or crashed, which kept them from completing the tasks. However, active participation overall is higher than the certification number may indicate at first sight and runs up to about $10 \%$, which can be concluded from active video viewing statistics, individual assignment submissions and other means of participation such as discussion contributions.

Even though it may be considered interesting that no participant mentioned the quality and content of the MOOC as the reason of not completing it, this cannot be claimed with certainty, as the sample for this survey can hardly represent the whole population of participants on this MOOC. The sharp drop between, for example, number of completed assignments between module 1 and 2 can be partially explained by the different nature of content and the difficulty of assignments: first one was more theory based and asked participants to take part in discussions and complete quizzes from the comfort of their homes or offices, 
while the second module demanded more engagement - examining mobile journalism technologies and producing video and audio stories in the field.

It can be assumed that this type of MOOC, that teaches practical skills in journalism, demands more time and effort from the participants. This perhaps explains their decision to drop out or the inability to find enough time to complete the tasks and dedicate themselves to learning. This confirms the already explored "destiny" of the MOOCs of having very low retention rates because they are timeconsuming. It can be suggested that the length of this particular MOOC of 20 weeks may have also influenced the decision of participants to stick until the end.

\subsection{Content and participant-trainer relationship}

Even though it could be expected that the lack of time may make participants impatient, the activity of viewing videos in this MOOC, which was one of the main resources for learning in all the modules, proves otherwise. The statistical data pulled from the project YouTube channel, where all the 98 video lessons were uploaded, gives a surprising picture, was encouraging for the team that designed this MOOC. See Figure 2 and Figure 3.

Figure 2: Number of views and duration of video lessons in the MOOC

\section{Number of views / duration of video}

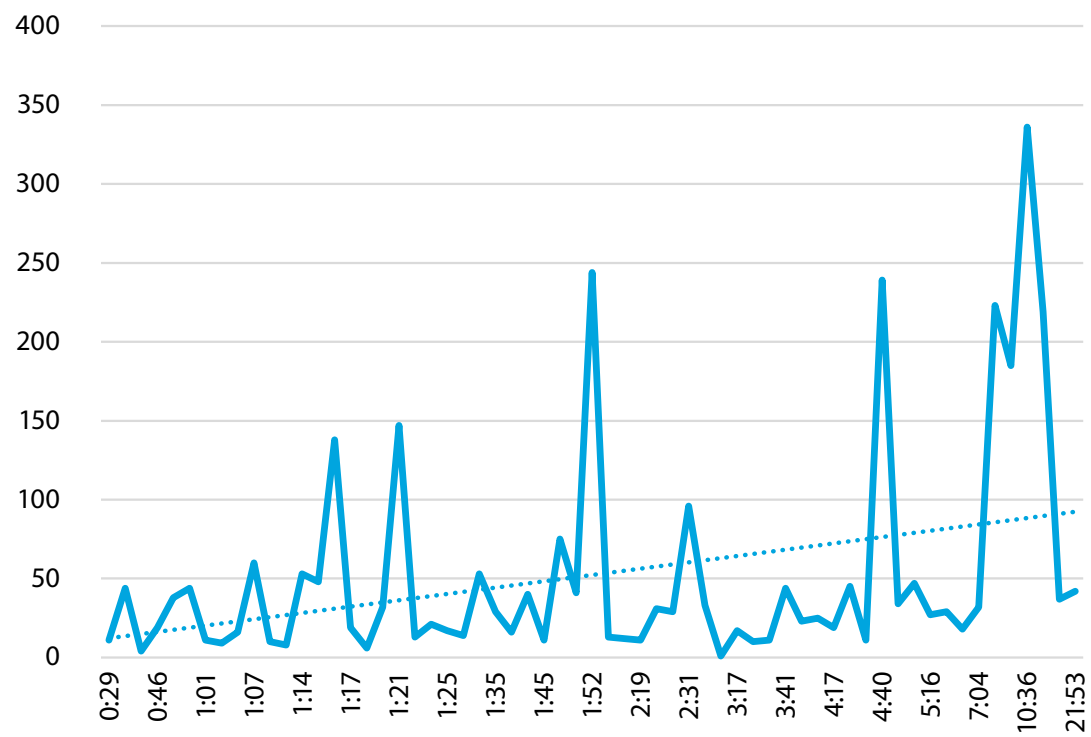




\section{Duration of videos and retention}

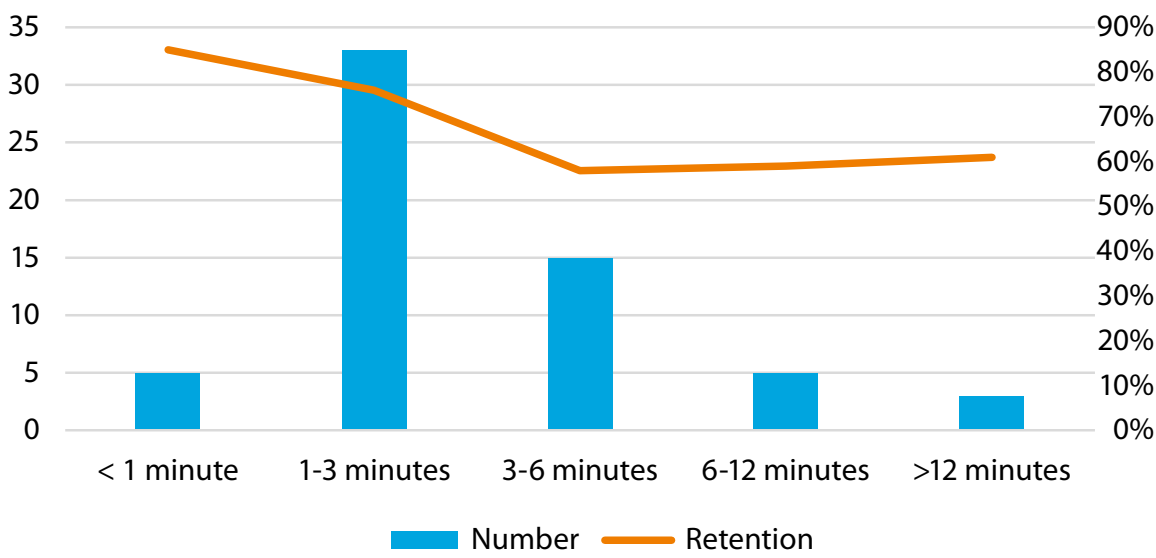

We can see that there is no visible correlation between the duration of the video and the number of times a video was viewed. Quite to the contrary, the number of views over duration of the video increases. This shows that longer videos and more rich content does not necessary mean losing participants, actually it may mean that serious MOOC participants, who are dedicated to completing the modules, are not bothered by duration. Participants that continue the MOOC until the end (a decreasing number over time of course) are more motivated to watch larger pieces or entire videos as they progress in the MOOC. Some videos were viewed more than once by some participants. This is perhaps a positive encouragement for journalism education in this way as it proves that interested participants are prepared to do more work and they have patience for longer content.

In both surveys participants were asked to assess the level of their satisfaction with the course. Results show overall a very high satisfaction and interest in the course and its content, however this should not be taken for granted because it is expected that those who managed to participate in the course for almost four months probably would not have had if they did not like it. When asked to elaborate and describe what they liked most about the MOOC, many times the answer was simply "Everything". The second thing respondents em- 
phasized they liked most was the communication and the effort of remote trainers in this MOOC. Another thing that respondents liked most was the content itself, as well as the participation in discussion in which they could exchange views with their tutors, but also with other participants. Here are some of the other answers they submitted about other advantages of the course:

- I liked the "immersiveness" in the tasks which needed to be completed.

- interesting examples from journalists" everyday life, really detailed feedback for some tasks, flexible deadlines

- Real life situations

- It taught me about this new perspective of pursuing people and their story from mobile point of view. Now I can easily distinguish relevant from less important and I know how to present information to public the right way that is objective as much as possible, informative, balanced and truthful.

- New skills that were very simplified and well explained.

- That I could join the classes whenever I felt like it.

- They were quite active, and at the same time not pushing which for me is a must. Some of us are already working so sometimes is a bit difficult to keep up to date. They have been very professional and helpful. Thank you very much for the useful feedback.

- The tasks for put in practice the learning.

- The whole module is worth studying again and again.

- I'd say discussions we had through forum really helped me to see bigger picture of mobile journalism as well as of professional ethics, so I think those forums were useful. Also I liked all of practical tasks and I wished there was more of them because they push you to go outside, to talk to variety of people and ask them about their story, and that's really important to know as journalist. I think using videos as the main platform to educate is genius because through interactive maps and video element, it made the course more interesting and fun.

Another valuable insight is the fact that respondents liked the tasks and real life situations they were required to cover as part of their assignments. Acquiring practical skills is one of the key aspects in journalism education and it seems it 
was one of the most inspiring and enjoying for remote learners as well. The practical tasks in remote journalism education might be, on the one hand, something that demands additional effort and may turn away participants with lack of time or willingness to do work in the field, while at the same time it is something that those who decide to dedicate the time to the course appreciate the most. It is no wonder that both trainers/tutors and the practical tasks are the most mentioned, as they are tightly connected to one another. The majority of learning in this course is focused on practical skills and their development depends both on the effort of participants, but also on the guidelines given by tutors.

When asked what they liked least about the MOOC, respondents mainly pointed out their own lack of time, a few expected more with regards to the quality of the tutoring while one respondent commented on a Facebook Live assignment he or she did not like. This shows that participants have different expectations from a course like this.

\section{Conclusions and recommendations}

The case of this MOOC proves that this specific way of remote learning could be suitable for mobile journalism education with further improvements. The predominant factor of low retention in this MOOC seems to be the lack of time that participants have at their disposal. Perhaps the success and level of completion in future MOOC courses in journalism education could be higher if their length is shorter.

As this MOOC was open to anyone, the use of this mode of learning as part of modules at schools, universities or professional organizations would perhaps prove to be more successful. This type of learning would prove to be a helpful additional tool in education of future or current journalists as part of their training.

For remote participants, the solution may be more condensed and shorter lessons and a heightened effort and availability of remote trainers who seem more important than ever in remote development of practical journalistic skills. Trainers and tutors in these kind of MOOCs should not only provide quality feedback for assignments and participate in discussions, but also find ways to further engage participants. For example, develop tasks that help participants connect and work together, as well as organize live video chats with practical exercises during which participants can ask questions. 
Fun and engaging practical tasks, along with rich content are also essential for a successful educational MOOC in journalism, however technical resources of remote participants should also be taken into consideration. Designers of MOOCs should be aware of this and think about alternatives and easy and cheap ways that enable remote students to acquire new journalistic skills, yet do not demand additional financial expenses.

In conclusion, the case of the Y-NEX MOOC in mobile journalism proves the potential of this type of journalistic education and the possibility to develop and refine practical journalistic skills by never physically meeting the trainers. However, more effort should be made in order to strengthen the communication between the participants and the trainers. Another serious consideration is the length of this type of MOOC. This case proves that perhaps shorter and more focused MOOCs would be more successful. Altogether, MOOC proved to be a suitable platform for mobile journalism education both for future journalists and those who want to improve their media literacy skills. 
Petra Kovačević

Tena Perišin
The perspective of using MOOCs in journalism education: Case study of mobile journalism MOOC users' experiences

\section{References}

Aharony, N. \& Bar-Illan, J. (2016). Students' Perceptions of MOOCs: An Exploratory Study. Interdisciplinary Journal of e-Skills and Life Long Learning, 12: $145-162$.

Alraimi, K., Zo, H. \& Ciganek, A. (2015). Understanding the MOOCs Continuance: The Role of Openness and Reputation. Computers \& Education, 80, 28-38.

Blankenship, J.C. (2016). Losing Their "MoJo"? Journalism Practice, 10(8): $1055-1071$.

Breslow, L., Pritchard, D. E., DeBoer, J., Stump, G. S., Ho, A. D. \& Seaton, D. T. (2013). Studying Learning in the Worldwide Classroom: Research into edX's First MOOC. Research and Practice in Assessment, 8:13-25.

Carey, J. (2000). Some Personal Notes on US Journalism Education. Journalism: Theory, Practice \& Criticism, 1(1):12-23.

Conboy, M. \& Eldridge, S. (2014). Morbid Symptoms: Between a dying and a re-birth (apologies to Gramsci). Journalism Studies, 15(5): 566-575.

Daradoumis, T., Bassi, R., Xhafa, F. \& Caballe, S. (2013). A Review on Massive E-Learning (MOOC) Design, Delivery and Assessment. 2013 Eighth International Conference on P2P, Parallel, Grid, Cloud and Internet Computing.

Gillmor, D. (2016). Towards a New Model for Journalism Education. Journalism Practice, 10(7): 815-819.

Hew, K. \& Cheung, W. (2014). Students' and Instructors' Use of Massive Open Online Courses (MOOCs): Motivations and Challenges. Educational Research Review, 12: 45-58.

Hone, K. \& El Said, G. (2016). Exploring the Factors Affecting MOOC Retention: A Survey Study. Computers \& Education, 98: 157-168.

Koltay, T. (2011.) The Media and the Literacies: Media Literacy, Information Literacy, Digital Literacy. Media Culture \& Society, 33(2): 211-221 
Kovačević, P. \& Perišin, T. (2016). Mobile Journalism Training: Best practices for Good Storytelling. In D. Pralica \& N. Šinković (eds.), Digitalne medijske tehnologije i društveno-obrazovne promene 6 (pp. 179-189). Novi Sad: Filozofski fakultet Novi Sad.

Kovach, B. \& Rosenstiel, T. (2007). The Elements of Journalism. 2nd ed. New York: Three Rivers Press.

Kraft, N. \& Seely, N. (2015). Making Mojos: How iPads Are Enhancing Mobile Journalism Education. Journalism \& Mass Communication Educator, 70(3): 220-234.

Kumar, A. \& Haneef, M.S.M. (2017). Is Mojo (En)De-Skilling?. Journalism Practice, Online First. doi:10.1080/17512786.2017.138291.

McAuley, A., Stewart, B., Siemens, G. \& Cormier, D. (2010). The MOOC Model for Digital Practice. http://www.elearnspace.org/Articles/MOOC_Final.pdf. Accessed on 15 September 2017.

Mensing, D. (2010). Rethinking (again) the future of journalism education. Journalism Studies, 11(4): 511-523.

Mills, J., Egglestone, P., Rashid, O. \& Vaataja, H. (2012). Mojo in Action: The Use of Mobiles in Conflict, Community and Cross-Platform Journalism. Continuum: Journal of Media \& Cultural Studies, 26(5): 669-683.

Picard, R. (2006). Journalism, Value Creation and the Future of News Organizations. Joan Shorenstein Center on the Press, Politics and Public Policy. Working Paper Series. Available at: http://www.robertpicard.net/PDFFiles/ ValueCreationsandNewsOrgs.pdf

Wenger, D. H., Owens, L. C. \& Thompson, P. (2014). Help Wanted 2010: An Examination of New Media Skills Required by Top U.S. News Companies. Journalism \& Mass Communication Educator, 67: 9-25. 